\title{
An integrated workflow to perform reservoir and completion parametric study on a shale gas reservoir
}

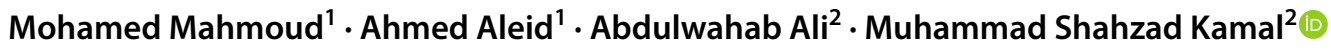

Received: 9 December 2019 / Accepted: 30 December 2019 / Published online: 6 January 2020

(c) The Author(s) 2020

\begin{abstract}
The main objectives of this paper are to assess the long-term and short-term production based on both reservoir parameters and completion parameters of shale gas reservoirs. The effects of the reservoir parameters (permeability and the initial reservoir pressure) and completion parameters (fracture geometry, stimulated reservoir volume, etc.) on the short-term and long-term production of shale gas reservoirs were investigated. The currently used approach relies mainly on the decline curve analysis or analogs from a similar shale play to forecast the gas production from shale gas reservoirs. Both these approaches are not satisfactory because they are calibrated on short production history and do not assess the impact of uncertainty in reservoir and well data. For the first time, this study integrates initial production analysis, probabilistic evaluation, and sensitivity analysis to develop a robust workflow that will help in designing a sustainable production from shale gas plays. The reservoir and completion parameters were collected from different available resources, and the probability distributions of gathered uncertain data were defined. Then analytical models were used to forecast the production. Two well evaluation results are presented in this paper. Based on the results, completion parameters affected the short-term and long-term production, while the reservoir parameters controlled the long-term production. Long-term well performance was mainly controlled by the fracture half-length and fracture height, whereas other completion and reservoir parameters have an insignificant effect. Stimulation treatment design defines the initial well performance, while well placement decision defines well long-term performance. The findings of this study would help in better understanding the production performance of shale gas reservoirs, maximizing production by selecting effective completion parameters and considering the governing reservoir parameters. Moreover, it would help in accomplishing more effective stimulation treatments and define the potentiality of the basin.
\end{abstract}

Keywords Unconventional shale gas · Long-term and short-term production · Reservoir and completion parameters · Probabilistic approach

\section{Introduction}

Gas shale can be defined as any tight, fine-grained, organicrich, gas self-sourced sedimentary formation. Gas shale contains all elements of a petroleum system and is a source rock, which provides hydrocarbons (Huaqing et al. 2018; Ma

Muhammad Shahzad Kamal

shahzadmalik@kfupm.edu.sa

1 Department of Petroleum Engineering, College of Petroleum Engineering and Geoscience, King Fahd University of Petroleum and Minerals, Dhahran 31261, Saudi Arabia

2 Center for Integrative Petroleum Research, College of Petroleum Engineering and Geoscience, King Fahd University of Petroleum and Minerals, Dhahran 31261, Saudi Arabia et al. 2018; Xianggang et al. 2018; Mahmoud et al. 2019; Wei et al. 2019; He et al. 2019). As high as fifty percent of gas by weight can be formed through the maturation of organic material within the shale. The generated gas is trapped within shale adsorbed in the organic/clay material or free inside pores. As shale is relatively impermeable and the rate of hydrocarbon generation far exceeds the rate of outflow, hydrocarbons accumulate within shale formations. Thus, unconventional shale will trap most of the gas/oil in spite of their high pressure due to the low permeability (Dejam 2019a).

Shale has nanoscale pores with dimensions ranging from several nanometers to few micrometers (Qiu et al. Qiu et al. 2019a, b; Tan et al. 2019). Due to the nanoscale pores, the flow regime in the shale matrix is defined by slip flow and transition flow (Fig. 1). Hence, the Darcy flow model is not 


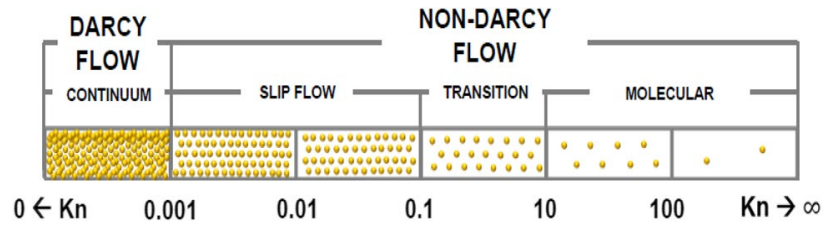

Fig. 1 Flow regimes as per Knudsen in the microscopic porous medium [1]

applicable to the shale rock matrix, and the shale permeability is expected to be in the order of nano-Darcy (Blasingame 2015; Dejam et al. 2017a, b). However, Darcy flow occurs both in the open natural fractures and fissures and in the induced fractures of the shale formation.

As shale gas reservoirs are very tight, they have to be drilled horizontally to produce economically. Large fractures must be created along these horizontal wells to produce commercially from shale gas reservoirs. The geometry of the created fracture(s) depends on many variables, including the pumping rate and pressure, pad volume, fluid viscosity, proppant concentration, in situ stress, and rock fabric (Dejam et al. 2018; Kou and Dejam 2018; Zhang et al. 2018; Olayiwola and Dejam 2019; Dejam 2019b). Ideally, a fracture grows in the same plane as the well in both length and height and can reach other formations with higher in situ stress barriers. A fracture continues to grow in length until the end of the pumping treatment. The resulting fracture is planar and extends in a bi-wing manner away from the wellbore. Hence, they are normally called bi-wing, planar, or simple fractures (Smith and Montgomery 2015). Other fracture geometries may occur due to many reasons, including the existence of natural fractures and low-stress anisotropy (Sayers and Le 2010). Due to micro-seismic activities, four possible fracture geometries can be present in hydraulically fractured reservoirs (Mattar et al. 2006; Gomaa et al. 2017). As the performance of a well in shale reservoirs is highly influenced by the geometry of the fractures created and the hydraulic fracture signal is inseparable from the reservoir signal, it is essential to understand the complexity of the fractures. Moreover, a complex fracture geometry is sought in stimulation treatment because it not only connects more rock surface area to the wellbore but also enhances the effective permeability of the reservoir by activating more natural fractures and fissures. Such a complex fracture geometry is identified as a stimulated reservoir volume (SRV). Although the effect of an SRV on a conventional reservoir is minor, it is significant in shale gas reservoirs. Gomaa et al. (2017) have shown that the fracture complexity can be controlled by controlling the viscosity of the fracturing fluid. SRV creation can extend far beyond the induced fractures, and this can be detected from the micro-seismic activities (Ehlig-Economides and Economides 2011). An SRV is created when the fracturing water is imbibed by the high capillary shale, preventing fractures from closing and acting as a conduit for the hydrocarbons to flow to the induced fracture (Anderson et al. 2010). Other studies have also examined the role of the fracture fluid in determining the extent of production. Only quarter to half of the pumped fluid is recovered in shale stimulation operations, with the rest of the fluid remaining trapped in the reservoir. In actual practice, it is generally considered a bad sign to recover more stimulation treatment fluid (Gomaa et al. 2014).

Published reports indicate that researchers have extensively studied and modeled the effects of adsorption of shale gas and coalbed methane. Fan et al. (2018) have shown that the micropores highly affect the gas adsorption in shale gas reservoirs (Fan et al. 2018). The approach they used will help better estimate the gas content in shale gas reservoirs. Zhao et al. have shown that there is a critical pore size that affects the adsorption of coalbed methane during the water injection process (Zhao et al. 2018a). Wang et al. (2017) have studied the effects of the competitive adsorption of methane and carbon dioxide on the adsorption of shale gas (Wang et al. 2017). They found that the organic pores (pores in organic matter) have a higher adsorption capacity for $\mathrm{CO}_{2}$ compared to methane although the self-diffusion of methane is larger than that of $\mathrm{CO}_{2}$. In addition, they indicate that the direction, i.e., whether the adsorption is horizontal or vertical, has a major effect on the adsorption capacity. Horizontal adsorption is higher than vertical adsorption.

Many empirical, analytical, and numerical solutions to analyze production data in porous formations are available in the published literature. Arps was the first to analyze declining rates in producing wells empirically (Arps 1945). His models predict the future rate and the expected ultimate recovery (EUR) based on the production history of the wells as long as the production is stable and a BDF (boundary dominated flow) has prevailed. In shale formations, transient flow typically lasts for years and the application of Arps's equations during this period tends to overestimate future production. Conventional well test analysis methods are currently used to analyze the production from shale gas reservoirs. Well test analysis requires long shut-in periods to analyze shale, and this method is not practical because of the unavailability of suitable shut-in periods. Hence, rate transient analysis is more commonly used to analyze shale reservoirs (Blasingame and Lee 1988; Ilk et al. 2008). Other methods have been suggested for the analysis of production from shale such as diagnostic analysis of production data (Ilk et al. 2010), deterministic workflow (Clarkson et al. 2011), and a generalized workflow that incorporates all transient analysis methods (Clarkson 2013).

The amount of gas held in shale gas sources exceeds that of conventional reservoirs. Commercial production of gas from unconventional resources has been made difficult 
due to many technical challenges. The advances in drilling and hydraulic fracture treatment have helped enhance the recovery by exposing more of the reservoir to the wellbore. However, production analysis leads to a non-unique solution for parameters such as the fracture half-length and permeability due to the lengthy transient period that a shale reservoir expresses.

A unified workflow for the analysis of the gas production from unconventional resources is not available in the literature, and all the previous analyses are subjective and depend on the analyzed cases. Until now, there is no single systematic approach in designing stimulation treatments for the shale gas reservoirs. Treatment parameters (such as lateral length, number of stages, and the conductivity of fracture) are subjective. In addition, there is high uncertainty in estimating reservoir and stimulation parameters such as permeability, initial pressure, and fracture half-length. The novelty in this study includes the integration of initial production analysis, probabilistic evaluation, and sensitivity analysis for the first time. The proposed workflow consists of various approaches that fits different data sets. Therefore, it can be easily generalized and applied to any shale gas play.

The objective of this paper is to evaluate the key parameters of reservoirs and wells that affect shale gas production. Reservoir parameters such as porosity, permeability, and the initial reservoir pressure will be evaluated. The completion parameters that will be investigated are well spacing, well length, fracture geometry, etc. Finally, an integrated production analysis workflow will be developed to be used as a guide for the production analysis from shale gas reservoirs.

\section{Methodology}

The proposed production analysis workflow consists of three major stages as shown in Fig. 2. They are (1) Stage 1: the initial production analysis, (2) Stage 2: the production evaluation using a probabilistic approach, and (3) Stage 3: parametric sensitivity.

In the initial production analysis stage, two wells in an unconventional shale gas reservoir were studied. The appropriate rate transient analysis is performed using IHS Harmony and Kappa Saphir, two software packages specially developed for the rate and pressure transient analysis. The software packages were used to analyze the available production and pressure data.

In the probabilistic evaluation stage, the probability distribution function is defined to obtain the completion parameters. Some parameters are more precise, while others have some level of uncertainty. For example, the well length and the reservoir temperature are more precise than the rock permeability and the fracture half-length. Reservoir parameters, such as permeability, porosity, initial pressure, and the reservoir extent, were evaluated. Completion parameters,

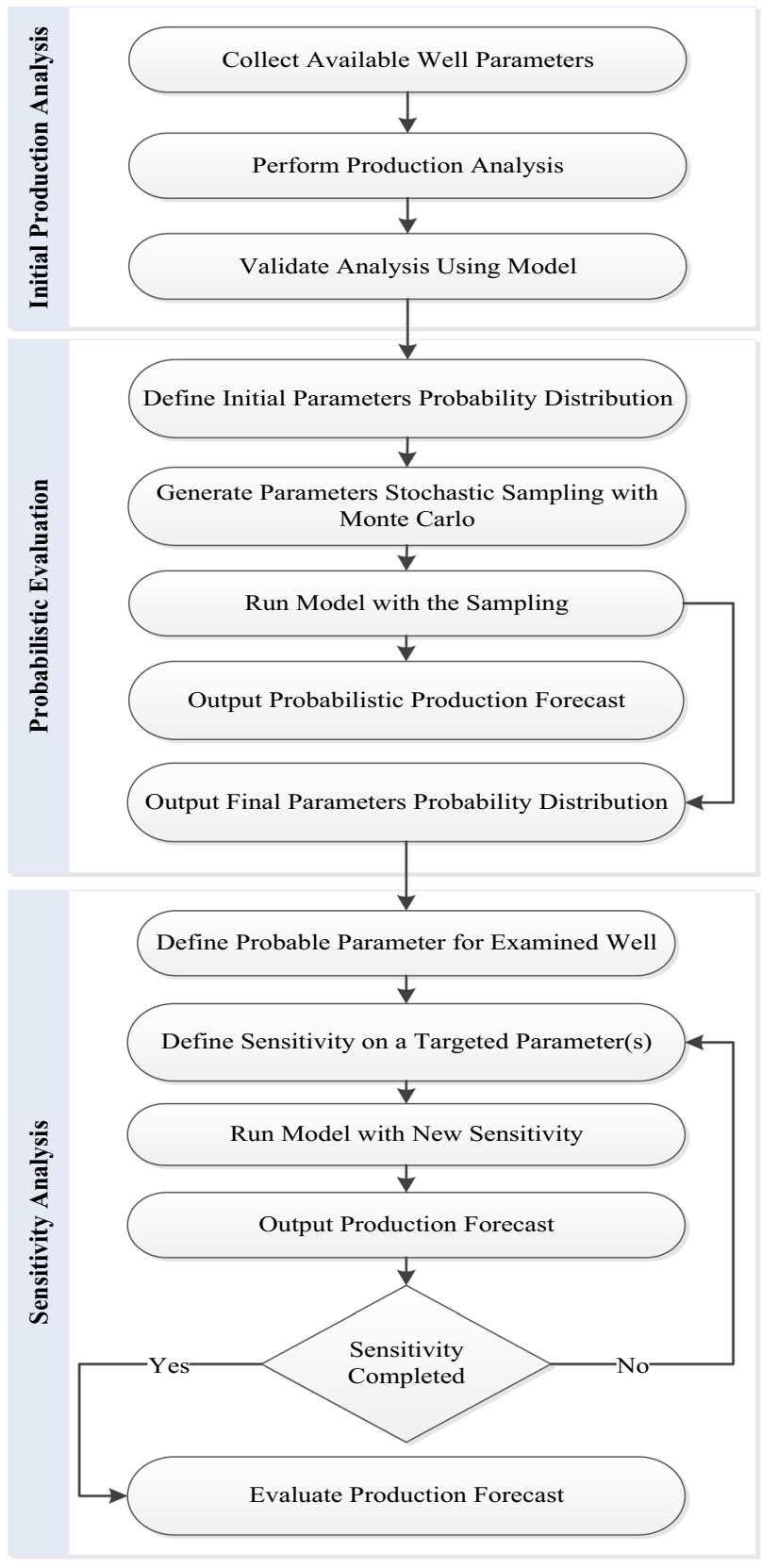

Fig. 2 Proposed workflow

including the number of fracture clusters, horizontal well length, well spacing, fracture height, fracture half-length, and fracture conductivity were also assessed. The main objective of the probabilistic evaluation stage is to reduce the uncertainty of unknown well and reservoir parameters. After the probability distributions of the parameters are defined, Monte Carlo simulation was used to construct the stochastic samplings of the parameters. Monte Carlo picks random samples for each parameter. The samples are then used to run the Composite Model numerous times. Thus, the uncertainties of the collected parameters are adequately reflected.

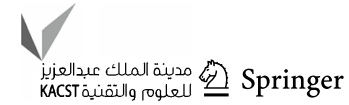


The model used in this paper considers the homogenous porosity, isotropic dual region permeability, well location in the center, constant pressure step, and shale lithology. The two main outcomes of the previous steps are the probabilistic production forecast and the probability distribution of the final parameters. The probabilistic forecast captures the likely production range of the subject well. The probability distribution of the final parameters would redefine the initial probability in light of the production forecast. In order to accomplish this task, @ Risk (MS Excel add-in) or IHS Harmony was used. @ Risk can define the probability distribution of each collected parameter and create Monte Carlo samplings. IHS Harmony can run the composite model and provide results.

In the sensitivity analysis stage, the impact of the well and reservoir parameters on gas production is investigated. A workflow similar to that used in the probabilistic evaluation is used, except that the probabilistic distribution of the final reservoir parameters is used. The sensitivity of the well and reservoir parameters would be repeatedly verified to obtain the production. In order to accomplish these tasks, IHS Harmony was used as the main tool.

\section{Results and discussion}

In this study, two multi-fractured horizontal wells drilled in a gas window of a shale gas basin were investigated. The two wells are producing the same fluids, and they are located close to each other.

The uncertainty of a range of parameters, such as fracture height $\left(h_{f}\right)$, fracture half-length $\left(x_{f}\right)$, number of fractures, reservoir permeability, reservoir initial pressure, and fluid properties, was investigated. In multi-fractured horizontal wells drilled in a shale gas reservoir, the unknown parameters are more than the known parameters. Fracture height is the most uncertain parameter among them because an accurate or direct method to determine the fracture height in horizontal wells is not available. The fracture height in vertical wells can be determined using temperature and acoustic, pulsed neutron, or radioactive tracer surveys in a straightforward manner (Dobkins 1981; Anderson et al. 1986; Ahmed 1988; Velez et al. 2012; Goyal et al. 2017). Even though the fracture height in multi-fractured horizontal wells can be determined through well testing and simulation, a direct method such as in the case of vertical wells is not available. To reduce the uncertainty in the determination of the fracture height, it is considered as equal to the formation thickness.

The fracture half-length can be determined using gas well production data analysis. Long-term production data are required to determine accurate values of the fracture halflength. Several techniques and methods, such as production analysis, can be used to determine the fracture half-length
(Bybee 2004; Barree et al. 2005). Advisory systems built based on field experience in tight reservoirs to predict the fracture half-length have produced results that match well with those obtained from production data analysis (Wei and Holditch 2009). Micro-seismic monitoring can be used to determine the fracture half-length (Le Calvez et al. 2005). Production logging and production data can be integrated to evaluate the post-fracturing operation success (Jung 2017). Production history matching using proxy models has been used to characterize the fractures and production from shale gas reservoirs (Kim et al. 2017).

Regarding the permeability of a reservoir, two permeability values are of interest. They are the non-stimulated rock permeability or the outer permeability, and the stimulated rock permeability or the inner permeability. The maximal inner permeability is estimated from the linear flow behavior using Eq. (1) (Spivey and Lee 2013):

$\left(\frac{p_{i}-p_{\mathrm{wf}}}{q}\right)=m_{L} \sqrt{t}+b_{L} S_{f}$

where $p_{i}$ is the initial reservoir pressure, $p_{\mathrm{wf}}$ is the bottomhole flowing pressure, $q$ is the gas flow rate, $\mathrm{m}_{\mathrm{L}}$ is the slope of the linear flow region, $t$ is the time, $b_{L}$ is the intercept, and $S_{f}$ is the fracture face skin. The outer permeability of the stimulated reservoir volume (SRV) can be estimated using the diagnostic fracture injection test (DFIT).

Accurate initial reservoir pressure can be determined using post-closure analysis. If the direct measurement of the pressure is not available, an estimation can be used from nearby wells. The upper limit of the initial pressure should not exceed the fracture gradient pressure, and lower limit can be considered as that estimated from the pressure buildup test.

For a near-critical fluid such as condensate gas, a full PVT study on an early bottom-hole sample is highly recommended. If it is not available, the equation of state (EOS) calibrated using a recombined wellhead sample can be used.

In this paper, two wells drilled in a shale gas reservoir were analyzed. The two wells have produced for several months at a high gas/oil ratio. The reservoir temperature is $270{ }^{\circ} \mathrm{F}$, the flowing bottom-hole pressure was set to be a minimum of $100 \mathrm{psi}$, the reservoir length is $4812 \mathrm{ft}$, and the reservoir width is $1300 \mathrm{ft}$. The reservoir height is $93 \mathrm{ft}$, and the reservoir rock bulk density is $2.5 \mathrm{~g} / \mathrm{cm}^{3}$.

\section{Initial production analysis}

The first step in data analysis is to convert the surface readings to bottom-hole values. This was achieved by uploading the well configurations along with the fluid properties and the production history to the well performance simulator PROSPER. Subsequently, the normalized rate versus the 
normalized material balance time was plotted to identify the flow regimes. Material balance pseudo-time $\left(t_{\mathrm{mb}}\right)$ can be calculated using Eq. (2):

$t_{\mathrm{mb}}=\frac{\mu_{i} C_{t i}}{q} \int_{0}^{t} \frac{q}{\bar{\mu} \bar{C}_{t}} \mathrm{~d} t$

where $\mu$ is the gas viscosity, $C_{t}$ is the total compressibility, and $q$ is the gas flow rate. The calculated pseudo-time is normalized to obtain the maximum material balance time (MBT). The rate is divided by pseudo-pressure $\left(P_{P}\right)$ calculated using Eq. (3).

$p_{p}=\frac{\mu_{i}}{\rho_{i}} \int_{p_{i}}^{p} \frac{\rho}{\mu} \mathrm{d} p$

where $\rho$ is the gas density. By dividing the rate by $p_{p}$, the highest normalized rate is obtained. Two flow regimes, namely bilinear flow, and linear flow were clearly identified with no sign of transition to boundary dominated flow (BDF) (Fig. 3). The bilinear flow attributed to fracture cleanup, lasted for 2 months, recovering about $13.5 \%$ of the fracturing fluid pumped into the reservoir during the fracturing operations. Subsequently, the stabilization of the gas/water ratio (GWR) was observed producing $50 \mathrm{bbl} / \mathrm{MMscf}$ of gas, indicating that the well cleanup period has ended. As only a linear flow exists, the minimum SRV and the maximum SRV permeability can also be estimated.

Next, the normalized gas production rate versus the square root of the gas production time was used to estimate the product of the fracture half-length and the square root of permeability $\left(x_{f} \sqrt{k}\right)$ (Fig. 4). The slope of the straight line in Fig. 4 is $30 \mathrm{mD}^{0.5} \mathrm{ft}$ and it is the product $x_{f} \sqrt{k}$, according to Eq. 1. Also, Eq. 4 defines the maximum SRV permeability using the time of the end of linear flow and fracture spacing. Finally, the minimum SRV was estimated by extrapolation in the flowing material balance time plot (Fig. 5).

$k=\frac{1896 \phi C_{t} d_{i}^{2}}{t_{\text {elf }}}$

The trilinear composite model was used to model production utilizing the input data extracted from straight-line analysis. The rectangular model with 45 equally spaced fractures was also used to model production. Initial completion parameters and the estimations of the straight-line analysis are used as initial input for the model, and regression of inner permeability, fracture half-length, and fracture conductivity was performed. The predictions of the model provided an excellent match with the production history as shown in Fig. 6.

\section{Probabilistic evaluation}

In this stage, the uncertainty overlooked in stage 1 is considered and evaluated. Each fixed parameter in the previous stage is now given an initial distribution (Table 1). Correlation between porosity and saturation was assumed to be a positive correlation, and that between the fracture numbers and fracture half-length was assumed to be a negative correlation. Next, a simulation was performed to refine the assumed distribution and to forecast the possible production. The initial and final distribution of the parameters is summarized in Table 1. Figure 7 shows P10, P50, and P90 forecast for Well 1 and Well 2. Fracture networks and fracture number are two of the major parameters that affect gas production from shale gas reservoirs (Xue et al. 2018).

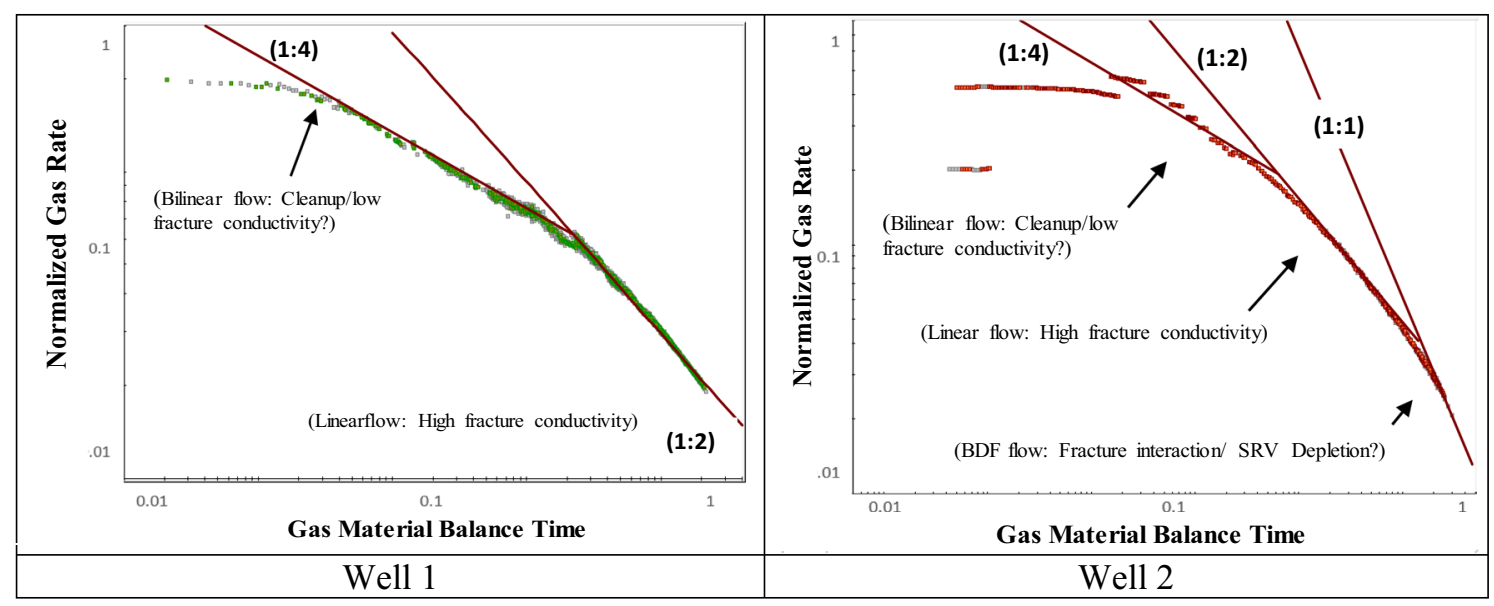

Fig. 3 Normalized gas production rate versus material balance time (log-log scale) 


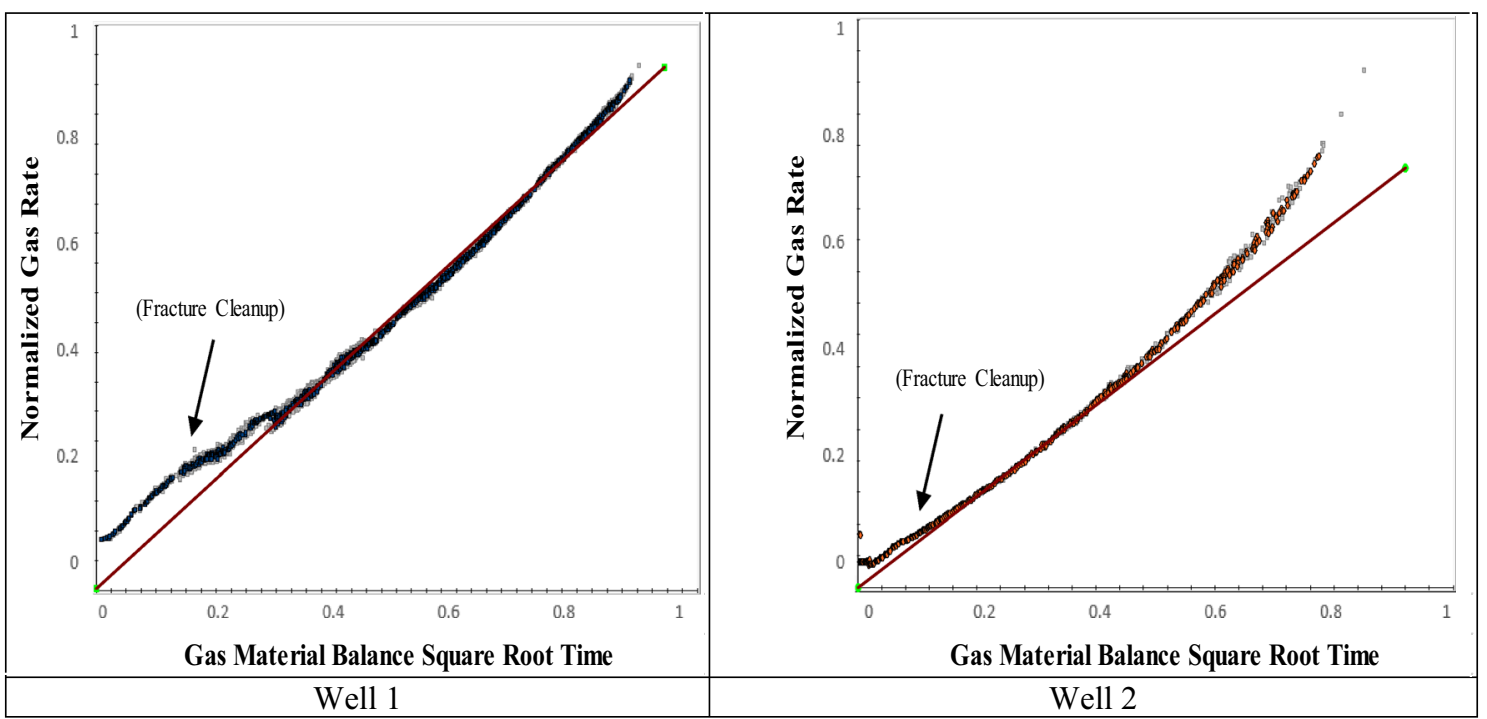

Fig. 4 Square root time plot versus normalized gas rate

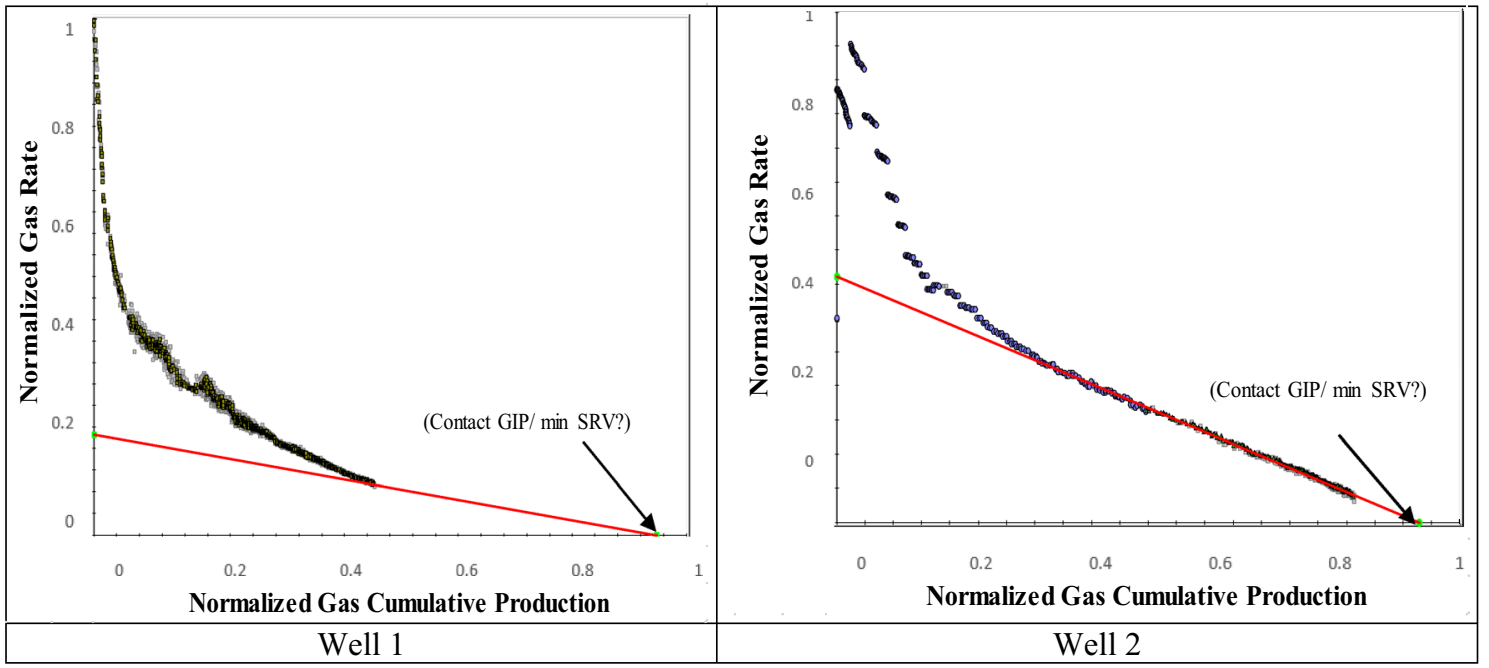

Fig. 5 Flowing material balance plot

\section{Sensitivity analysis}

The probabilistic analysis provides a better understanding of the likely completion and reservoir parameters. The mean value of the final distribution in Table 1 was fed to the created trilinear composite model to develop a base case scenario. Following that, the sensitivities of the main reservoir and the completion parameters were input into the model, and model was run for the equivalent of 30 years in order to determine the impact of each parameter. Results were plotted on both Cartesian and logarithmic scales and normalized to the base case maximum value to evaluate the performance from different angles. The following results were obtained from the sensitivity analysis.
The production is directly proportional to the fracture half-length. The longer the fracture half-length of the fractures formed, the higher the rate of production and the cumulative production. The ratio of the increase in the production to the increase in the fracture half-length is $1: 2$ (Fig. 8). The duration of the flow regimes is not affected by the fracture half-length.

The production is directly proportional to the number of fractures. More the fractures formed, the higher the initial rate of production and the cumulative production. The increase in the initial rate only lasts for at most a year. The ratio between the production increases after the equivalent of 30 years, and the fracture number increase 


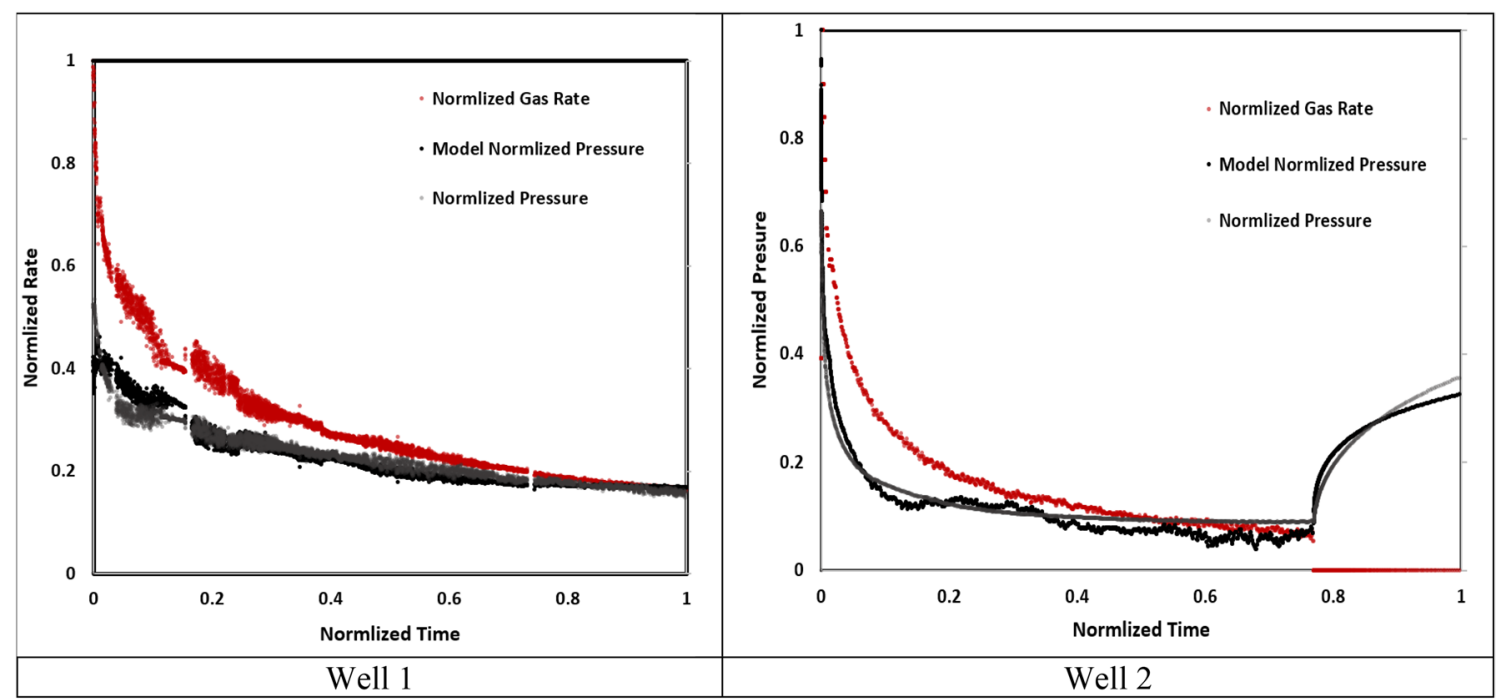

Fig. 6 Well production history match

Table 1 Initial and final distribution of uncertain completion parameters

\begin{tabular}{|c|c|c|c|c|c|c|c|c|}
\hline \multirow[t]{2}{*}{ Parameters } & \multicolumn{4}{|l|}{ Initial distribution } & \multicolumn{4}{|l|}{ Final distribution } \\
\hline & Distribution type & Min & Max & Mean & Distribution type & Mean & $\mathrm{P} 10$ & P90 \\
\hline Number of fractures & Triangular & 32 & 63 & 48 & Normal & 47 & 57 & 38 \\
\hline Fracture half-length (ft) & Uniform & 30 & 250 & - & Log-normal & 118 & 208 & 46 \\
\hline Fracture conductivity (N/A) & Uniform & 5 & 300 & - & Normal & 21 & 32 & 16 \\
\hline Inner permeability & Uniform & 90 & 400 & - & Log-normal & 162 & 290 & 117 \\
\hline Outer permeability & Uniform & 20 & 90 & - & Log-normal & 25 & 34 & 20 \\
\hline
\end{tabular}

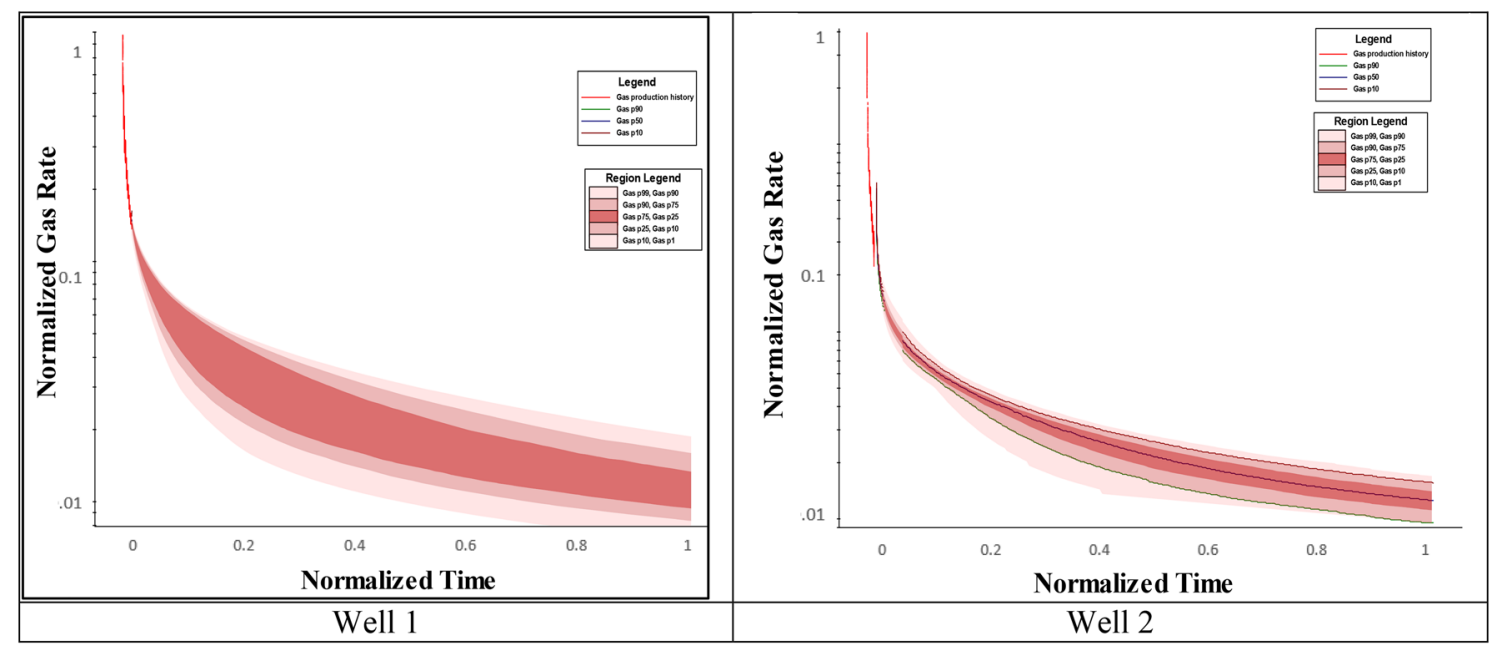

Fig. 7 Forecasted Normalized Gas Rate Versus Normalized Time (Semi-Log Scale)

is 3:5 (Fig. 9). More the number of fractures, the shorter the transition period between the first linear flow and BDF.

The production is directly proportional to the well length. However, the relationship weakens when the well length is longer. The effect of longer wells appears after 1 year of production. The ratio between the increase in the production after 30 years and the longer well is $3: 5$ 


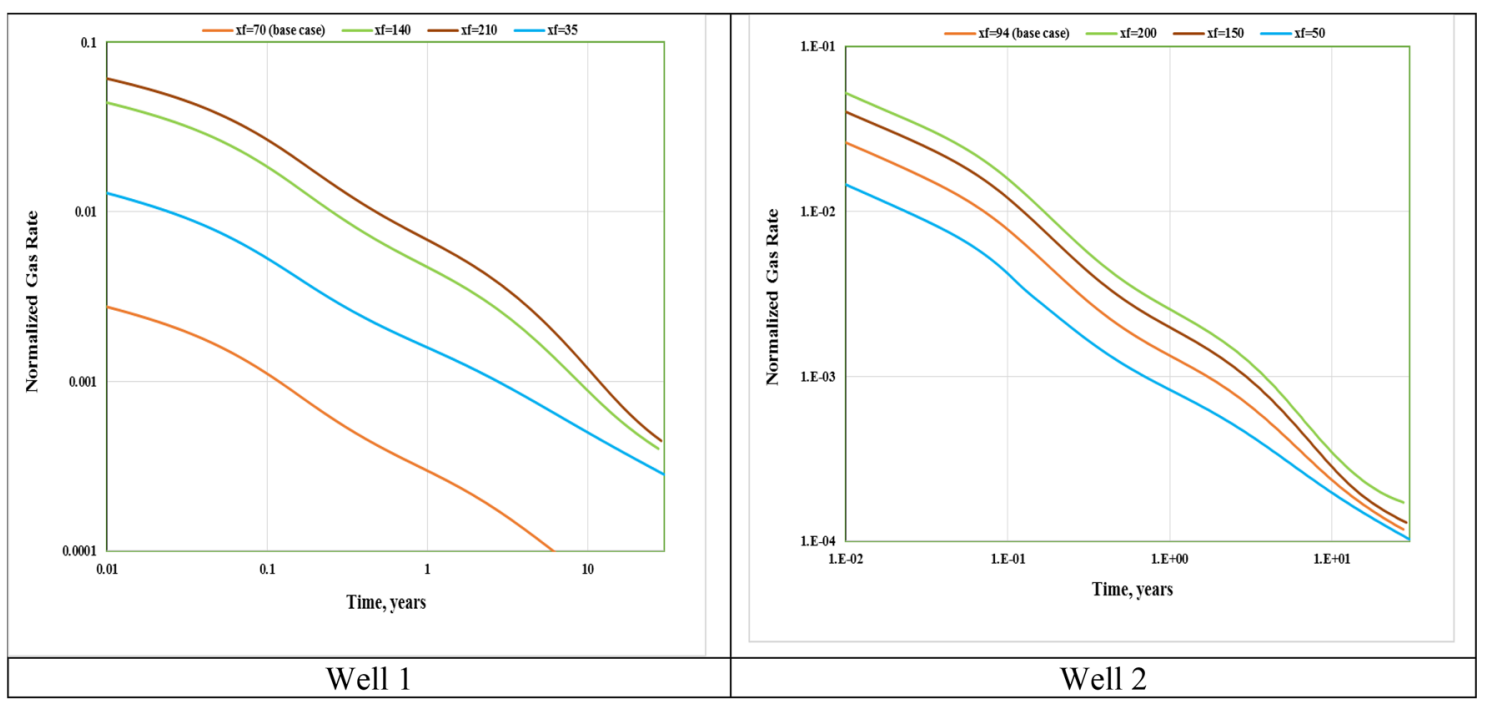

Fig. 8 Fracture half-length sensitivity

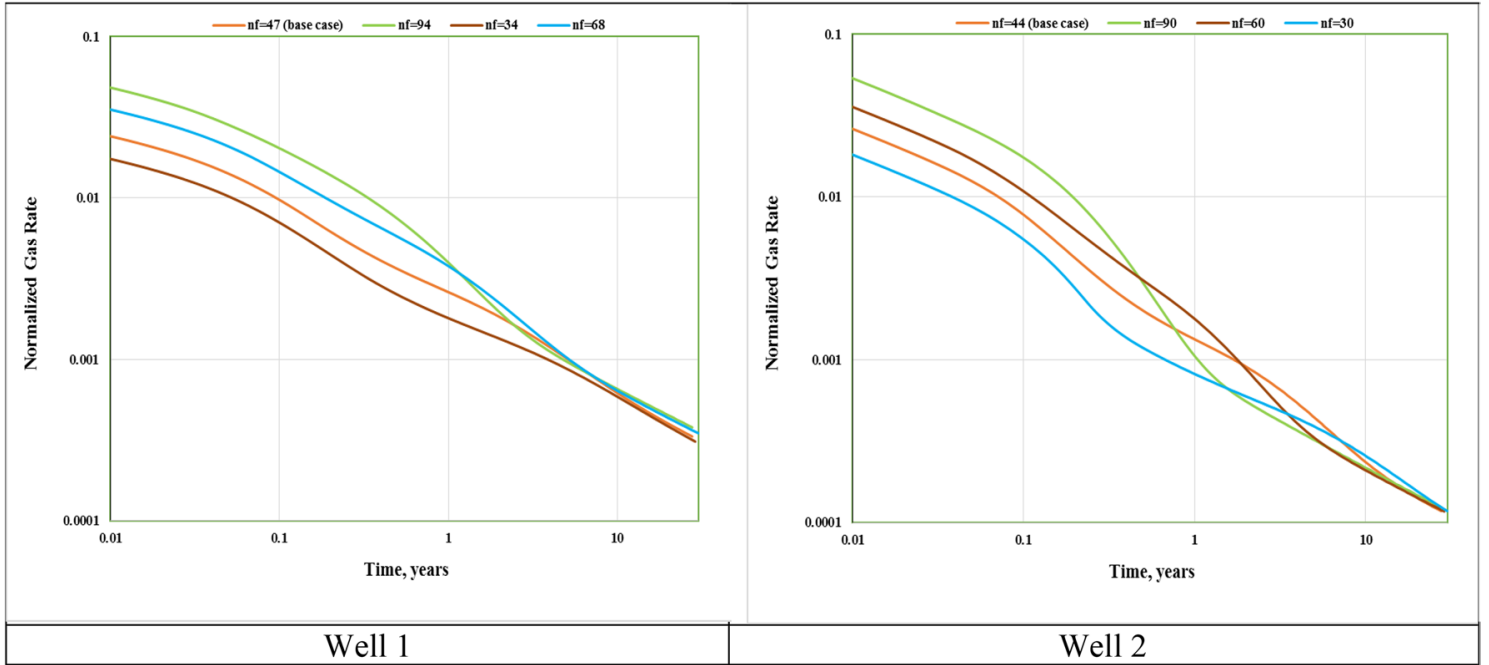

Fig. 9 Fracture number sensitivity

(Fig. 10). Longer wells delay the BDF regime and extend the linear flow regime.

The production is directly proportional to the fracture conductivity. However, the effect of more conductive fractures is negligible and is only apparent for the first few days lasting only for a few months (Fig. 11). Fracture conductivity does not affect the duration of the flow regimes.

The production is directly proportional to the well spacing. The effect of a larger spacing is initially negligible and is only apparent in the last few years of production. However, a small spacing that is really close to the fracture length shortens the well life significantly and thus decreases the production (Fig. 12). Well spacing does not affect the duration of the flow regimes.
The production is directly proportional to the fracture height. The higher the fractures formed, the higher the rate of production and the cumulative production. The ratio of the increase in the production and the increase in the fracture half-length is 1:1 (Fig. 13). The duration of the flow regimes is not affected by the fracture half-length.

The production is directly proportional to the inner permeability. The increase of production due higher permeability is negligible (Fig. 14). The effect of the higher permeability is initially significantly high and is apparent only in the first few months of production. A higher permeability shortens the initial linear flow regime.

The production is directly proportional to the outer permeability. The ratio of the change in production to the 


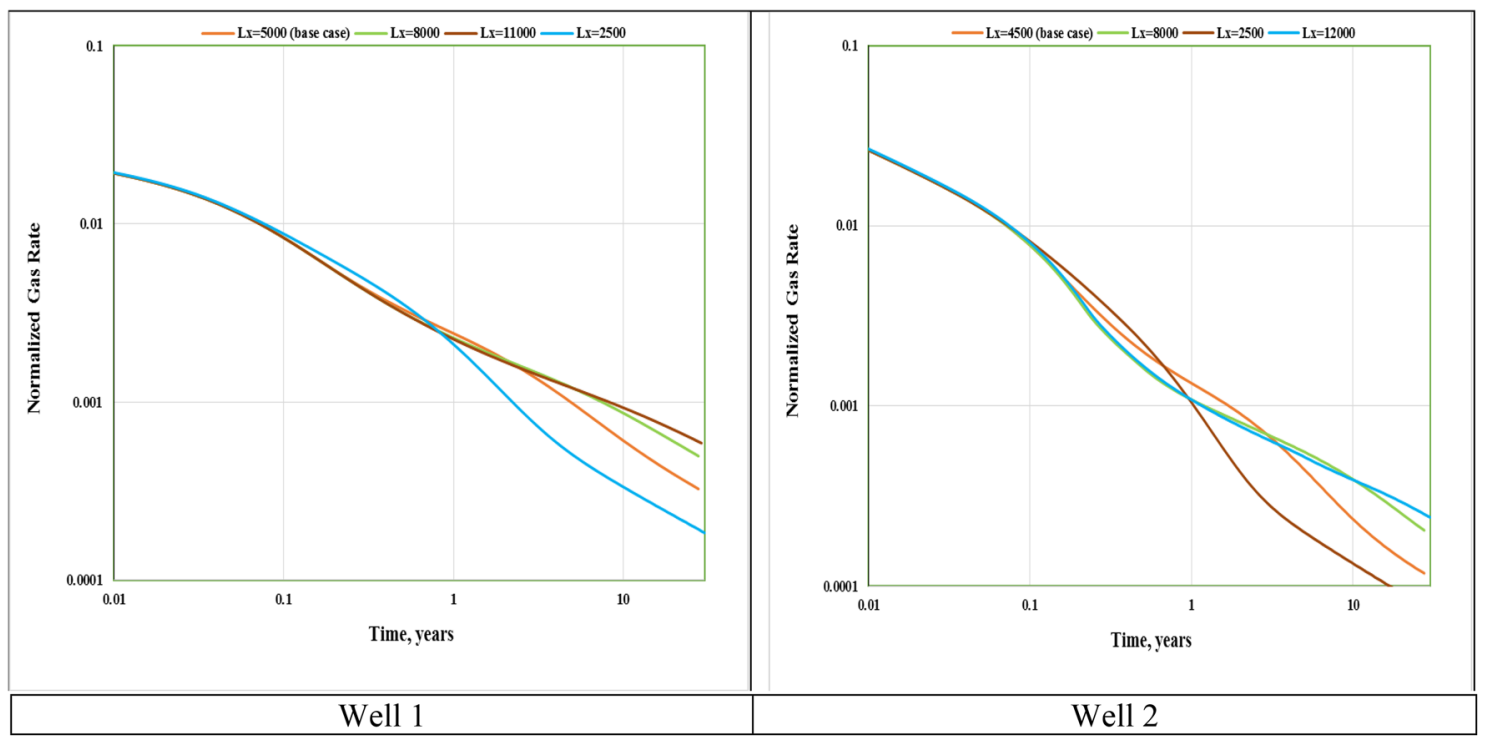

Fig. 10 Well length sensitivity

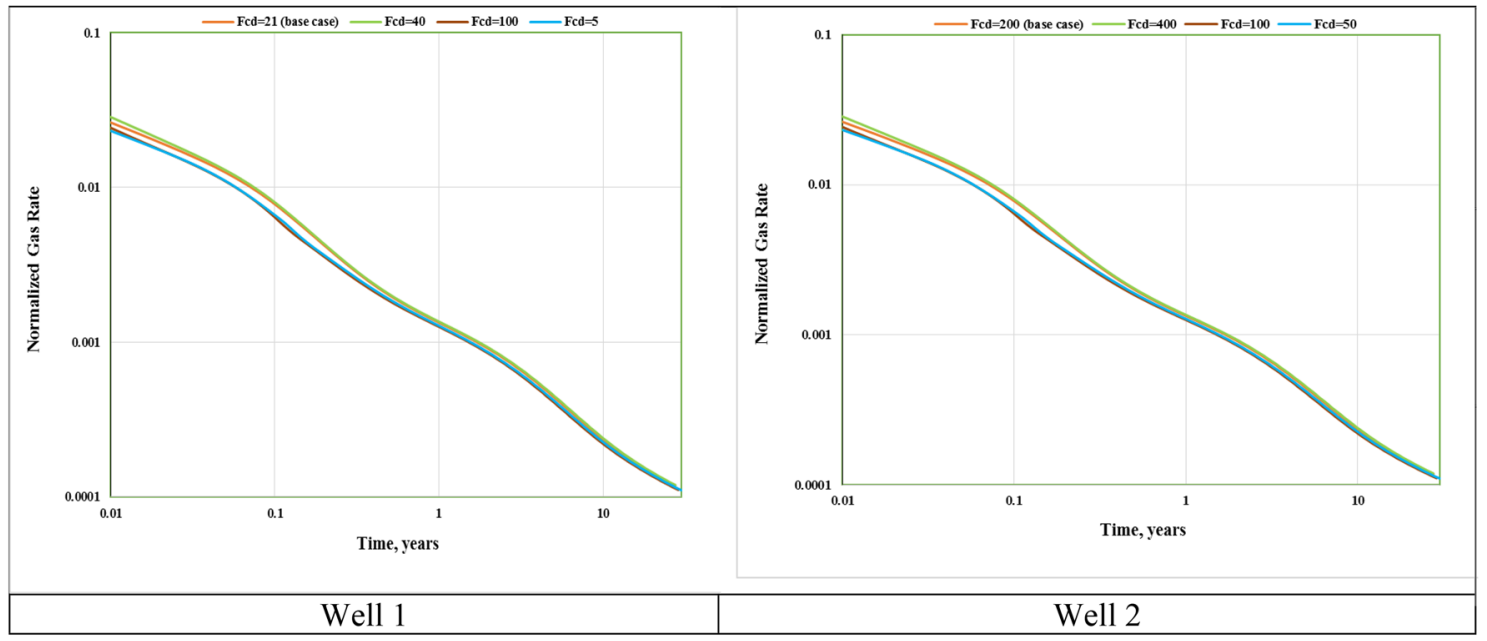

Fig. 11 Fracture conductivity sensitivity

change in permeability is 4:5 (Fig. 15). The effect of the higher permeability is initially negligible and is apparent only after the first linear flow regime. A higher permeability shortens the transition between different flow regimes.

The production is directly proportional to the porosity. The effect of higher porosity is significant after the initial flow regime. The ratio of the change in production to the change in porosity is 1:2 (Fig. 16). The duration of the flow regimes is not affected by the change in porosity.

The production is directly proportional to the adsorption. The effect of higher adsorption is significantly high after the initial flow. The ratio of the change in production to the change in adsorption is 2:1 (Fig. 17). The duration of the flow regimes is not affected by a change in the adsorption. Previous studies showed that gas adsorption is correlated with the TOC content and maturity (Zhao et al. 2018b).

\section{Conclusions}

After examining two different cases of gas wells in an unconventional gas play, the following conclusions are derived:

1. Cleanup period (bilinear flow) lasts for few weeks compared to months in other shale plays, and this can be attributed to the careful planning of drilling fluids. 


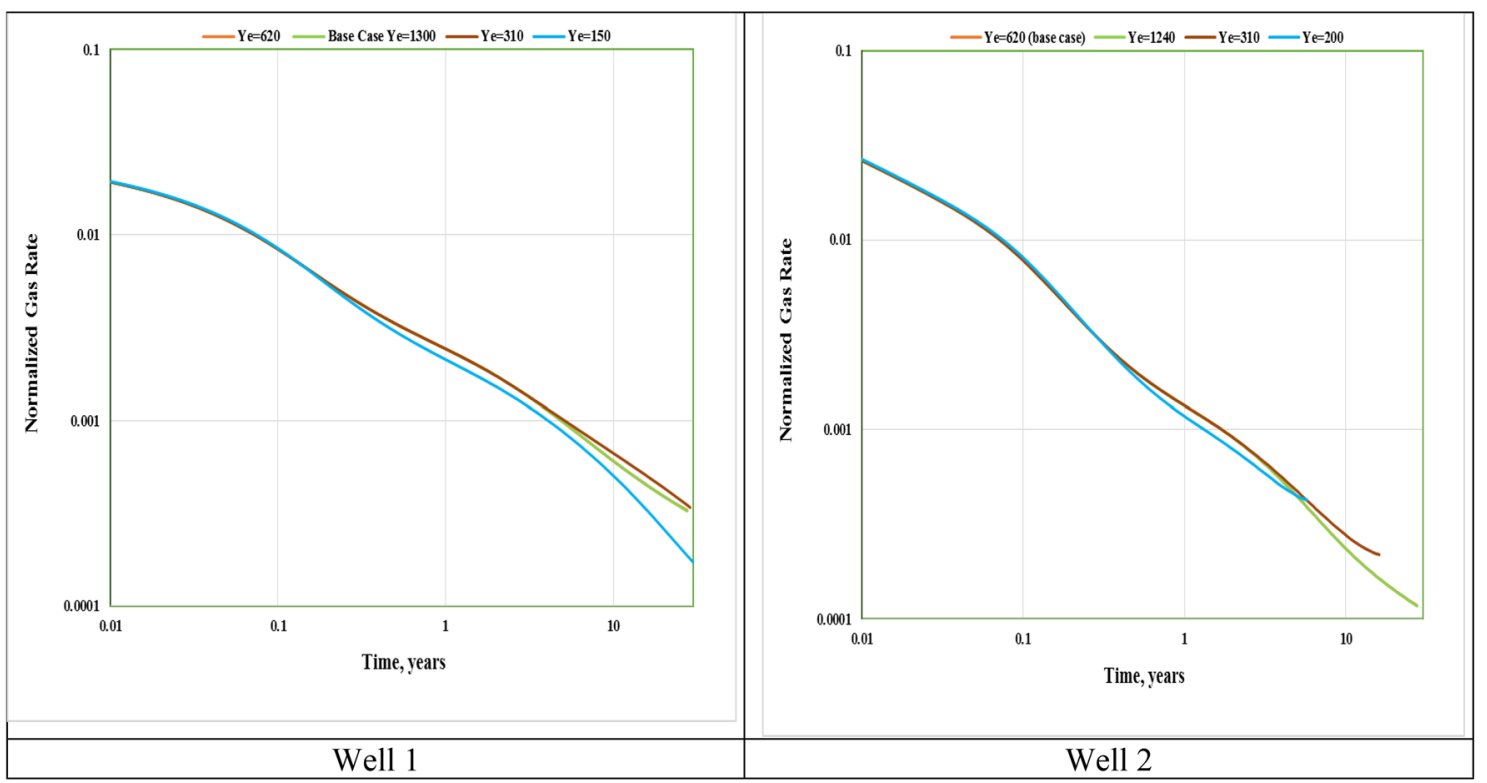

Fig. 12 Well spacing sensitivity

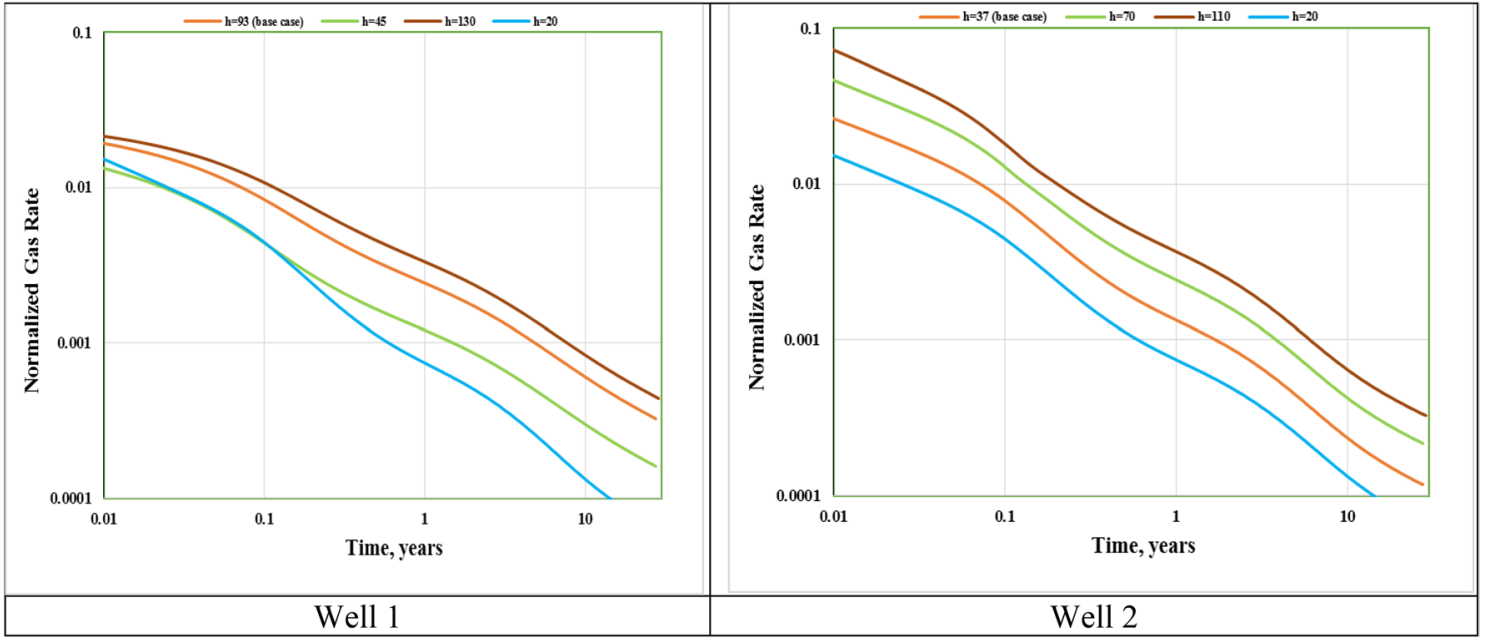

Fig. 13 Fracture height sensitivity

2. Linear flow seems to last for few months at most, indicating a high permeability or intensive stimulation treatment.

3. The probabilistic approach was the only way to estimate gas in place and stimulated reservoir volume because of the unclear indication of reservoir boundary.

4. All cases indicate a limited fracture size (especially Well 2 ), and EUR can be doubled by doubling the fracture half-length.

5. Different well and reservoir parameters have dissimilar effects on the performance and the duration of the flow regimes.
- In general, the completion parameters affect the initial short-term well performance, while the reservoir parameters impact the long-term well performance.

- The transient flow regime is greatly affected by the fracture number, inner permeability, and well length.

- The fracture conductivity affects the performance of the wells only for the first few days or weeks of production.

- Outer permeability and well spacing affect only the BDF regime.

- Adsorption affects performance during BDF flow and delays depletion. 


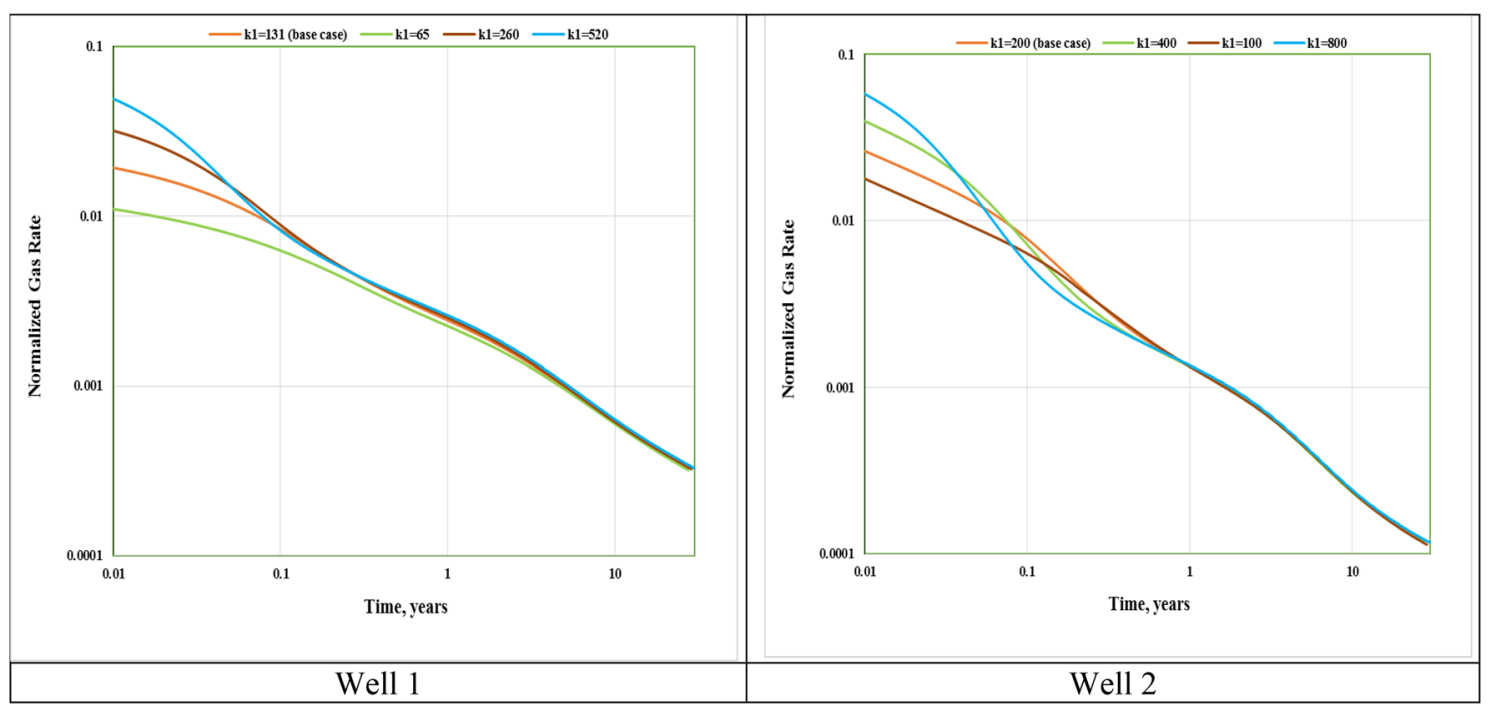

Fig. 14 Inner permeability sensitivity

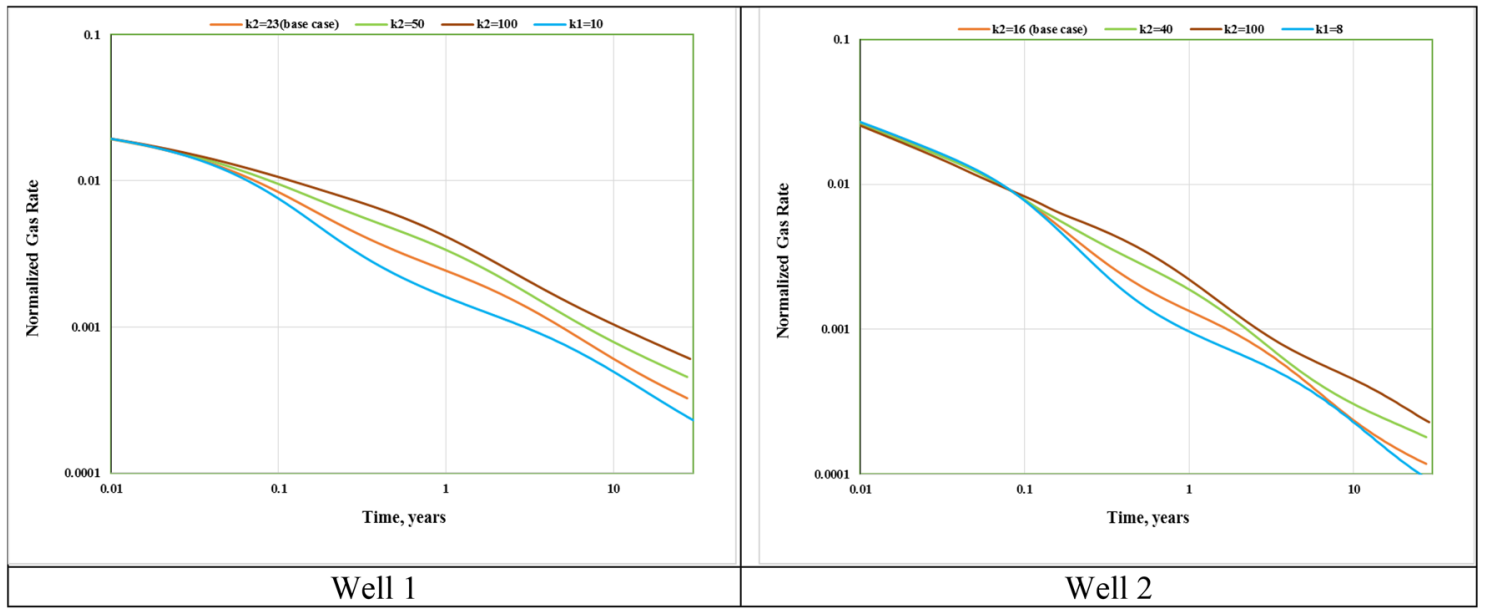

Fig. 15 Outer permeability sensitivity

- While the well spacing significantly affects the well life, its effect on EUR is minimal. However, well spacing does not affect the well performance.
6. Well performance is mainly affected by the fracture half-length, height, and number followed by the set of parameters including the porosity, permeability, and well length and then by the set of parameters including the well spacing, fracture conductivity, adsorption, and initial pressure. 


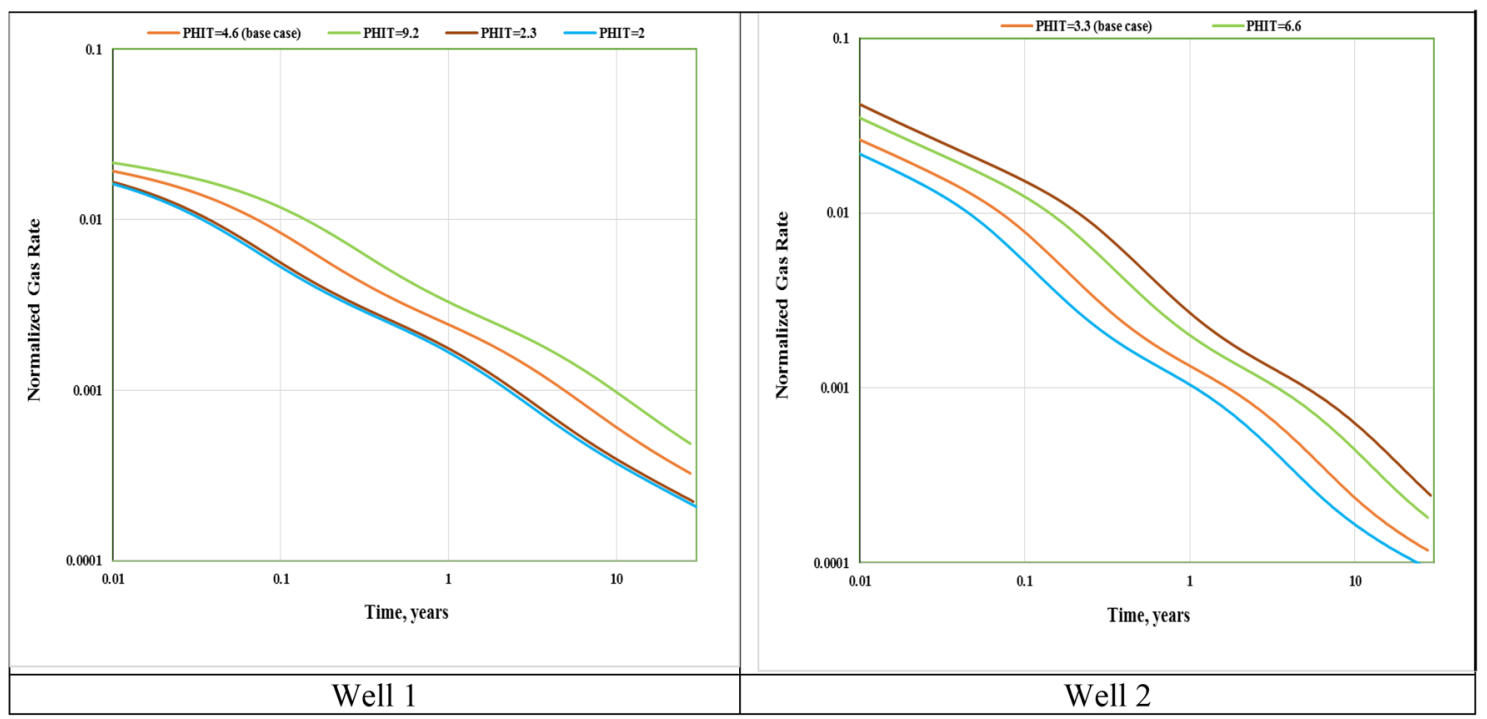

Fig. 16 Porosity sensitivity

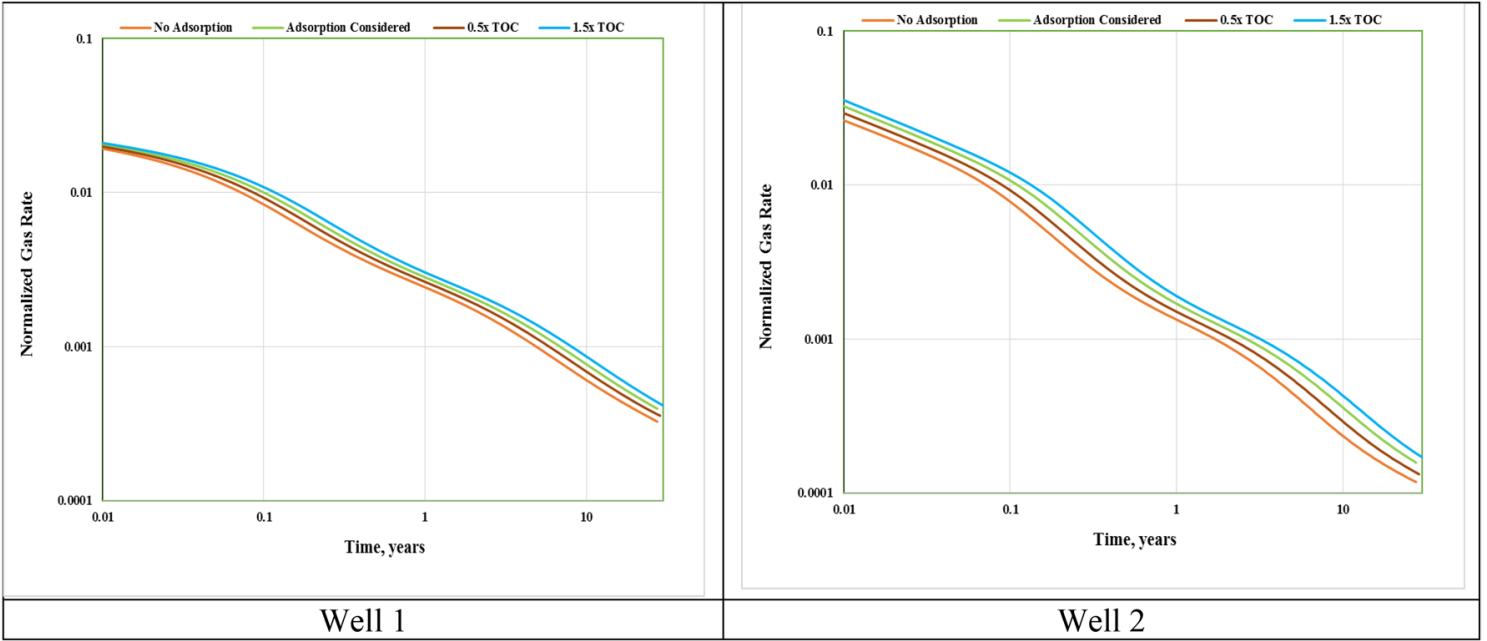

Fig. 17 Adsorption sensitivity

Open Access This article is licensed under a Creative Commons Attribution 4.0 International License, which permits use, sharing, adaptation, distribution and reproduction in any medium or format, as long as you give appropriate credit to the original author(s) and the source, provide a link to the Creative Commons licence, and indicate if changes were made. The images or other third party material in this article are included in the article's Creative Commons licence, unless indicated otherwise in a credit line to the material. If material is not included in the article's Creative Commons licence and your intended use is not permitted by statutory regulation or exceeds the permitted use, you will need to obtain permission directly from the copyright holder. To view a copy of this licence, visit http://creativecommons.org/licenses/by/4.0/.

\section{References}

Ahmed U (1988) Fracture height prediction. J Pet Technol 40:813-815 Anderson JA, Pearson CM, Abou-Sayed AS, Meyers GD (1986) Determination of fracture height by spectral gamma log analysis. In: SPE Annual technical conference and exhibition. Society of petroleum engineers

Anderson DM, Nobakht M, Moghadam S, Mattar L (2010) Analysis of production data from fractured shale gas wells. In: SPE unconventional gas conference. Society of petroleum engineers

Arps JJ (1945) Analysis of decline curves. Trans AIME 160:228-247

Barree RD, Cox SA, Gilbert JV, Dobson ML (2005) Closing the gap: fracture half length from design, buildup, and production analysis. SPE Prod Facil 20:274-285

Blasingame T (2015) Reservoir engineering aspects of unconventional reservoirs. SPE webinar 
Blasingame TA, Lee WJ (1988) The variable-rate reservoir limits testing of gas wells. In: SPE gas technology symposium. Society of petroleum engineers

Bybee K (2004) Hydraulic fracturing: fracture half-length from design, buildup, and production analyses. J Pet Technol $56: 41-43$

Clarkson CR (2013) Production data analysis of unconventional gas wells: workflow. Int J Coal Geol 109:147-157

Clarkson CR, Jensen JL, Blasingame T (2011) Reservoir engineering for unconventional reservoirs: what do we have to consider? In: North American unconventional gas conference and exhibition. Society of petroleum engineers

Dejam M (2019a) Advective-diffusive-reactive solute transport due to non-Newtonian fluid flows in a fracture surrounded by a tight porous medium. Int J Heat Mass Transf 128:1307-1321. https:// doi.org/10.1016/j.ijheatmasstransfer.2018.09.061

Dejam M (2019b) Tracer dispersion in a hydraulic fracture with porous walls. Chem Eng Res Des 150:169-178. https://doi.org/10.1016/j. cherd.2019.07.027

Dejam M, Hassanzadeh H, Chen Z (2017a) Pre-Darcy flow in tight and shale formations. APS Q35:011

Dejam M, Hassanzadeh H, Chen Z (2017b) Pre-Darcy Flow in Porous Media. Water Resour Res 53:8187-8210. https://doi. org/10.1002/2017WR021257

Dejam M, Hassanzadeh H, Chen Z (2018) Semi-analytical solution for pressure transient analysis of a hydraulically fractured vertical well in a bounded dual-porosity reservoir. J Hydrol 565:289-301

Dobkins TA (1981) Improved methods to determine hydraulic fracture height. J Pet Technol 33:719-726

Ehlig-Economides CA, Economides MJ (2011) Water as proppant. In: SPE Annual technical conference and exhibition. Society of petroleum engineers

Fan Z, Hou J, Ge X et al (2018) Investigating influential factors of the gas absorption capacity in shale reservoirs using integrated petrophysical, mineralogical and geochemical experiments: a case study. Energies 11:3078

Gomaa AM, Qu Q, Nelson S, Maharidge R (2014) New insights into shale fracturing treatment design. In: SPE/EAGE European unconventional resources conference and exhibition

Gomaa AM, San-Roman-Alerigi DP, Al-Noaimi KR, Al-Muntasheri GA (2017) Fractured well productivity: proppant pack vs. pillar fracture-numerical study. In: SPE Kingdom of Saudi Arabia annual technical symposium and exhibition. society of petroleum engineers

Goyal R, Tiwari S, Tibbles RJ, et al (2017) Fracture height determination using pulsed neutron capture in near vertical wells of deep tight gas volcanic reservoir of western india: case study. In: SPE/ IATMI Asia pacific oil \& gas conference and exhibition. Society of petroleum engineers

He L, Mei H, Hu X et al (2019) Advanced flowing material balance to determine original gas in place of shale gas considering adsorption hysteresis. SPE Reserv Eval Eng. https://doi.org/10.2118/19558 1-pa

Ilk D, Perego AD, Rushing JA, Blasingame TA (2008) Integrating multiple production analysis techniques to assess tight gas sand reserves: defining a new paradigm for industry best practices. In: CIPC/SPE gas technology symposium 2008 joint conference. Society of petroleum engineers

Ilk D, Anderson DM, Stotts GWJ et al (2010) Production data analysischallenges, pitfalls, diagnostics. SPE Reserv Eval Eng 13:538-552

Jung S (2017) Integration of the production logging tool and production data for post-fracturing evaluation by the ensemble smoother. Energies 10:859

Kim J, Kang J, Park C et al (2017) Multi-objective history matching with a proxy model for the characterization of production performances at the shale gas reservoir. Energies 10:579
Kou Z, Dejam M (2018) A mathematical model for a hydraulically fractured well in a coal seam reservoir by considering desorption, viscous flow, and diffusion. Bull Am Phys Soc 63(13)

Le Calvez JH, Bennett L, Tanner KV et al (2005) Monitoring microseismic fracture development to optimize stimulation and production in aging fields. Lead Edge 24:72-75

Ma YS, Cai XY, Zhao PR (2018) China's shale gas exploration and development: understanding and practice. Pet Explor Dev 45:589-603

Mahmoud M, Eliebid M, Al-Yousef HY et al (2019) Impact of methane adsorption on tight rock permeability measurements using pulsedecay. Petroleum 5:382-387

Mattar L, Rushing JA, Anderson DM (2006) Production data analysischallenges, pitfalls, diagnostics. In: SPE Annual technical conference and exhibition. Society of petroleum engineers

Olayiwola SO, Dejam M (2019) A comprehensive review on interaction of nanoparticles with low salinity water and surfactant for enhanced oil recovery in sandstone and carbonate reservoirs. Fuel 241:1045-1057

Qiu X, Tan S, Dejam M et al (2019a) Simple and accurate isochoric differential scanning calorimetry measurements: phase transitions for pure fluids and mixtures in nanopores. Phys Chem Chem Phys 21(1):224

Qiu X, Tan SP, Dejam M, Adidharma H (2019b) Experimental study on the criticality of a methane/ethane mixture confined in nanoporous media. Langmuir 35:11635-11642. https://doi.org/10.1021/acs. langmuir.9b01399

Sayers CM, Calvez J Le (2010) Characterization of microseismic data in gas shales using the radius of gyration tensor. In: SEG Technical program expanded abstracts 2010. Society of exploration geophysicists, pp 2080-2084

Smith MB, Montgomery C (2015) Hydraulic fracturing. CRC Press, Boca Raton

Spivey JP, Lee WJ (2013) Applied well test interpretation. Society of Petroleum Engineers, Richardson

Tan SP, Qiu X, Dejam M, Adidharma H (2019) Critical point of fluid confined in nanopores: experimental detection and measurement. J Phys Chem C. https://doi.org/10.1021/acs.jpcc.9b00299

Velez E, Rodriguez L, Zambrano J, et al (2012) Fracture height determination with time-lapse borehole acoustics attributes. In: SPWLA 53rd annual logging symposium. Society of petrophysicists and well-log analysts

Wang Z, Li Y, Liu H et al (2017) Study on the adsorption, diffusion and permeation selectivity of shale gas in organics. Energies 10:142

Wei Y, Holditch SA (2009) Computing estimated values of optimal fracture half length in the tight gas sand advisor program. In: SPE hydraulic fracturing technology conference. Society of petroleum engineers

Wei M, Duan Y, Dong M et al (2019) Transient production decline behavior analysis for a multi-fractured horizontal well with discrete fracture networks in shale gas reservoirs. J Porous Media 22(3):343-361

Xianggang D, Zhiming HU, Shusheng GAO et al (2018) Shale high pressure isothermal adsorption curve and the production dynamic experiments of gas well. Pet Explor Dev 45:127-135

Xue H, Shangwen Z, Jian GY et al (2018a) Effects of hydration on the microstructure and physical properties of shale. Pet Explor Dev 45:1146-1153

Xue Y, Wu Y, Cheng L et al (2018b) An analytical model for multiple fractured shale gas wells considering fracture networks and dynamic gas properties. Arab J Geosci 11:551

Zhang L, Kou Z, Wang H et al (2018) Performance analysis for a model of a multi-wing hydraulically fractured vertical well in a coalbed methane gas reservoir. J Pet Sci Eng 166:104-120 
Zhao D, Gao T, Ma Y, Feng Z (2018a) Methane desorption characteristics of coal at different water injection pressures based on pore size distribution law. Energies 11:2345

Zhao T, Li X, Ning Z et al (2018b) Pore structure and adsorption behavior of shale gas reservoir with influence of maturity: a case study of lower silurian longmaxi formation in China. Arab J Geosci 11:353
Publisher's Note Springer Nature remains neutral with regard to jurisdictional claims in published maps and institutional affiliations. 